\title{
Recognizing Intellectual Capital As An Asset
}

Mary Fischer, University of Texas at Tyler, USA

Treba Marsh, Stephen F. Austin State University, USA

\begin{abstract}
The revised definition of an asset by the FASB and GASB gives way to the recognition of the fair value of another off-balance sheet value. Interest in recognizing intellectual capital as an asset of the organization has grown out of dissatisfaction with traditional financial accounting and reporting directed toward manufacturing, trading of goods, and service activities which ignore the organizational asset values based on knowledge, expertise and technology. The growing interest in intellectual capital (IC) and knowledge management reflects an awareness of the need for identification, utilization, and measurement of an organization's most valuable asset. This paper identifies the importance of the IC value, discusses the research emphasis placed on it by others, and develops a fair value measurement model. The model provides a basis not only for identifying crucial aspects of effective knowledge management, but also for emphasizing the interdependence, and the synergy that may be created through recognition. Measurement techniques are presented together with a process for stakeholder communication that establishes the groundwork for future empirical investigation and analysis.
\end{abstract}

Keywords: Human Resources; Knowledge Management; Intellectual Capital

\section{BACKGROUND}

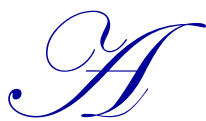

$\mathrm{s}$ business and other competitive enterprises become increasingly internationalized, competitive advantage based on traditional capital-intensive assets may become marginal. Where advantage exists, either domestically or internationally, is found not in financial or physical assets, but in the organization's knowledge base or assembled workforce, frequently labeled as intellectual capital or simply IC (Brooking, 1996, pp. 2-3).

This paper provides background and definition to the notion of IC and describes where and how it fits as an asset in the organization's financial valuation. It also is intended to provide an overview of the component elements of IC and how IC might be valued. The discussion adds to accounting literature by presenting IC in light of knowledge management. It couples this with the employment of measurement processes using a holistic approach.

IC is growing in importance as a key asset for the organization's success in today's economy. IC relates to intangible assets that comprise the accumulated replacement cost of the human resource value of an organization. These assets include a wide variety of things such as the acquisition cost to add or replace human resources, the set-up cost and separation costs when employees leave the organization. Additionally, the replacement of the knowledge held by the workforce should be part of IC assets. As time passes, this store of knowledge in an organization is believed to grow and show increasing complexity and diffusion (Lyles \& Schwenk, 1997, pp. 60-62). IC is not, however, simply free-floating human resources. Brooking (1996) and Evinsson and Malone (1997) provide extensive details regarding items that could be included as components under the umbrella of intellectual capital.

While most organizational analysts agree that IC exists, pinning it down for an individual, group of individuals, or an organization is difficult; and calculations to do so tend to lack scientific rigor. The financial markets provide evidence of the existence of hidden assets (i.e. assets not reported on a company's balance sheet) by way of market values that exceed the value of stated assets on the balance sheet. Management does not understand 
how to manage these assets (Conference Board, 1997). However, management does recognize that the organization has unrecognized reserves and hidden assets as a result of IC. What is missing is an agreed upon, valid and validated standard for measuring IC or its replacement cost.

Why have accountants avoided this area? Perhaps they have avoided the area because IC is believed to be difficult to quantify, as well as hard to value. Apparently many accountants and financial analysts ignore IC assets because the measurement has not been codified and is so difficult to define (Brennan, 1992). Traditional accounting systems offer little help in measuring and valuing this form of asset. Indeed, within the accounting profession there is a vigorous and ongoing debate about the wisdom and, indeed, the practicality of restructuring financial statements to reflect the hidden asset called IC (Evinsson \& Malone, 1997, pp. 23-39). However, there should be little debate about whether IC constitutes an "asset." IC meets all three of the essential characteristics of an asset:

1. IC is expected to contribute directly or indirectly to the future net cash flows of the business;

2. The entity can control access to IC; and

3. The transaction or event giving rise to the entity's right to, or control of, IC has already occurred (FASB 1985, par 26; FASB ASC 350, 2009; GASB, 2013).

The last two elements are transparent in the evaluation of assembled workforce as an asset. It can be argued that the entity has very little control over access, because in most cases, employees are free to leave an employer at their own choosing. It can also be argued that the transaction giving rise to the entity's right to, or control of, the workforce isn't a single transaction that has already occurred. An entity's level of control of its workforce seems to be comparable; however, to the level of control it has over goodwill. The value of a company's goodwill asset is largely the result of external factors such as company reputation and the perception of the marketplace that are, at best, indirectly under the control of the company. The recognition of goodwill as an asset on the balance sheet typically results from a specific transaction that has occurred in the past. The assembled workforce value is the result of past and future transactions between the company and its employees. This is not unlike other assets that entail future obligations for the company to maintain control of the asset, such as goodwill. Goodwill requires the ongoing "investment" of the company in order to maintain its value. This investment requirement could be viewed as a series of required future transactions between the company and the external market. Despite these similarities, goodwill is a recognized asset under Generally Accepted Accounting Principles, whereas the assembled workforce is not.

Both the Financial Accounting Standard Board (FASB) and Governmental Accounting Standard Board (GASB) have adopted fair value recognition as part of Generally Accepted Accounting Standards (GAAP) (FASB ASC 820, 2009; GASB, 2013). The four measurement attributes used in the measurement of the financial statement elements include historical cost, fair value, replacement cost, and settlement amount. The guidance aims to produce increased consistency in reported information and, therefore, increased comparability among companies A survey conducted by Ernst \& Young (2009) provides insight into the achievement of these goals. The survey concludes that little consistency and comparability exists in financial communication practices, even for companies in the same industry. GAAP provides replacement cost as a method to determine the price to acquire an asset with service potential and provides the basis for the recognition of human resource acquisition as an intangible asset.

The question of what constitutes value within an organization is much more than a debate about accounting and financial reporting. Its substance lies in the theory of a firm, its appropriate strategy position, and its movement toward the accomplishment of that strategy through appropriate organizational design and selection, retention, development, and compensation of human resources (Ulrich, 1997, pp. 23-51). In essence, the IC concept contributes much to the fundamental issue of achieving the organization's mission.

The growing importance of IC and human resource valuation, combined with the inadequacy of accounting processes, has resulted in considerable interest in the value of IC. A number of measurement and valuation proposals have been made and are in experimental stages, but as yet have not gained widespread acceptance. Slow acceptance stems from concerns such as 1) how valuing intellectual assets can benefit an organization, 2) what constitutes IC, and 3) a lack of accepted principles for identifying, measuring and valuing IC. 
This paper discusses these concerns together with other issues. The first section offers suggestions to define IC and its relation within the organization. Once defined, IC is discussed in light of the knowledge management process. With IC identified, human resource valuation measurement techniques are presented. Finally, a means to communicate the reality of IC to stakeholders is presented together with concluding remarks.

\section{INTELLECTUAL CAPITAL DEFINITION}

Defining IC is an elusive endeavor since the concept is evolving. It has been described as knowledge that exists in an organization to create differential advantage. Another definition labels IC as intellectual material that has been formalized, captured, and leveraged to produce a higher-valued asset. Stewart (1997, pp. 66-67) states that intelligence becomes an asset when some useful order is created out of free-floating brainpower - that is, when it is given a coherent form and it can be deployed to do something that could not be done if it remained scattered around like so many coins in a fountain. IC is packaged useful knowledge.

IC research and commentary have developed from several approaches. Table 1 outlines a categorization of approaches found in the IC literature although the approaches are often in combination or overlapping form. Major characteristics of IC are the structure of knowledge that is identifiable, can be accessed, can be shared, and has the potential to create value for the organization. It involves identifying, encouraging, and leveraging the organization's most potentially valuable real asset. Problems regarding label or identification terms arise because IC characteristics are not dissimilar, if different at all, from intangible assets or human capital where some portion of IC resides.

Table 1: Approaches to Intellectual Capital

A. Understanding that methods to identify intellectual capital in an organization include: determining its form, those who processes it, and how it adds value.

B. Creating intellectual capital or knowledge management databases that are repositories of the knowledge possessed by the organization. Many, but not all, are designed around information technology systems. Data may include:

- "Yellow pages" that identify persons and groups who have certain knowledge.

- Conference groups who meet on demand to solve problems and consider opportunities.

- Best practice repositories which are often stored in Excel or similar form.

- Target e-mail systems, such as Beehive, that search out experts on a question.

- Mentors who have "soft" knowledge that is difficult to document in data base form.

C. Fostering a "learning organization" in which the culture supports information sharing and mutual growth and development. These efforts include:

- $\quad$ Developing reward systems tied to knowledge sharing.

- Engaging in developmental training designed to encourage interpersonal and intergroup trust.

- Designing an organizational structure that empowers knowledge holders and knowledge seekers to solve problems and pursue opportunities through lateral collaboration.

D. Linking the core competencies and strategic plans of the organization to the knowledge base. Determining how to fully leverage available knowledge to more effectively accomplish strategic intent.

E. Designing formal and informal training and development methods to disseminate needed knowledge to appropriate organizational members.

F. Creating mechanisms for "unlearning" knowledge that is no longer needed as the organization adapts and changes.

G. Creating a measurement system that identifies the replacement value of intellectual assets and thus measures their contribution to the organization's value as well as their change in value over time.

Business literature uses the term IC to describe two different types of measures: asset values and performance indicators. The more traditional asset value measures relate to monetary values of identifiable intangible objects such as patents, copyrights, and trade secrets. Goodwill and a company's earning power of the assembled workforce are examples of other types of intangible assets that are often assigned a monetary value. Valuation of these assets employs generally accepted methods used by accountants or investment analysts. In addition to monetary measures, there are other types of measures that relate to the IC imbedded within an organization rather than being associated with identifiable objects. These types of measures are performance indicators that relate to business processes, continuous improvement efforts, and customer satisfaction and value. Performance indicators are typically expressed in a combination of monetary and nonmonetary terms. Their valuation tends not to be generally accepted, but rather is deemed experimental in nature. 
If it is true that the basic business model of any firm today is one which needs serious reexamination on a constant basis and the making of hard choices which require radical change frequently, it should be obvious that appropriate measurement of both external environmental needs and internal assets that do and can contribute to viability is a necessity. Precision of measurement aids in the central purpose of IC identification: the utilization and retention of the knowledge available to the organization in order to enhance its potential for optimum strategic outcomes. Thus, it may useful think of IC as the sum total of knowledge assets. Knowledge management is the process through which these assets are best put to use.

\section{KNOWLEDGE MANAGEMENT}

Given the relative infancy of the field of knowledge management, a normative model of the process appears necessary to suggest how IC identification, utilization, and retention can be effectively accomplished. The performance indicator approach is one of the earliest and best-known ways of addressing the problem.

There are a number of techniques for measuring IC using a performance indicator perspective. Two methodologies, the navigator (Skandia, 1995) and the balanced scorecard (Kaplan \& Norton, 1996), have common elements that focus on key business indicators. Each technique emphasizes performance measures rather than financial accounting measures and assumes an alignment of performance measures at all levels and in all units of the organization.

Skandia, a Swedish insurance and financial services company, introduced the navigator operating environment technique in its 1994 annual financial report supplement (Skandia, 1995). The philosophy behind the Skandia report is that traditional financial statements represent only past financial information about the company. Additional information about IC is needed to understand both a business's current and future capabilities. To fill this void Skandia developed a framework that combined traditional financial reporting with measures of IC. Evinsson and Malone (1997, p. 68) developed an illustration of the navigator's operating environment that displays the environment measurement.

Conversely, the balanced scorecard is a performance measurement system that links key indicators to business strategy (Kaplan \& Norton, 1996, p. 9). These indicators are balanced between financial and nonfinancial numbers rather than being focused only on traditional financial measures from historical cost accounting systems. The balanced scorecard is used to guide business decisions and evaluate the performance of managers at all levels and in all units of a business.

The balanced scorecard is intended to serve as a central management system for implementing a company's strategic vision. This means that the scorecard provides a linkage between goals and measures at all levels of the organization. Also, the scorecard integrates long-range strategic plans with short-term measurable objectives. However, for the balanced scorecard to succeed, McCann (1998, p. 35) found that organizations must know what they are hoping to achieve.

Lev (2001) has a further variant of the scorecard form: the Value Chain Scoreboard that identifies three phases in the value chain. Lev suggests possible perspectives within each component that might furnish insightful measures of an organization's value creation activities. Another value scorecard approach suggested by McLean (1999) was part of the Canadian Institute of Chartered Accountants Performance Reporting Initiative that adopted a value creation emphasis rather than the traditional value realization emphasis of financial accounting and reporting. Although both the navigator and various other scorecards assume synergy dynamics, none explicitly address the retention or replacement costs of the assembled workforce.

As an effort to suggest a more holistic approach to the organization's value, a model for human resource replacement cost determination is presented as an integrating tool for this purpose. 
Table 2: Human Resource Organizational Value

\begin{tabular}{|l|l|l|l|}
\hline & \multicolumn{1}{|c|}{ Direct Costs } & \multicolumn{1}{|c|}{ Indirect Costs } \\
\hline Total Acquisition Cost $=$ & $\begin{array}{l}\text { Recruitment Selection: Hiring (i.e., moving } \\
\text { expense) Placement (office set up) }\end{array}$ & + & Promotion cost: Internal cost \\
\hline Total Set-up Costs $=$ & Training Orientation On-the-job & + & Trainers' fee \\
\hline Total Separation Cost $=$ & $\begin{array}{l}\text { Replacement salary change Loss of efficiency } \\
\text { Salary savings }\end{array}$ & + & $\begin{array}{l}\text { Benefit/burden increase } \\
\text { (Benefit/burden avoided) }\end{array}$ \\
\hline Total Human Resource Asset value $=$ & Total Acquisition Cost + Total Set-up Costs + Total Separation Cost \\
\hline
\end{tabular}

The major utility of the model is its ability to differentiate the various components of the human resource replacement valuation. Not only does it recognize the importance of identification, measurement, and valuation, it emphasizes the strategic importance of evaluating the entire system by the components. Developing a recognition culture that supports and encourages an assembled workforce replacement valuation is a fundamental step for optimal knowledge management.

\section{VALUATION DETERMINATION}

The growing importance of IC, combined with the inadequacy of traditional accounting systems, has resulted in considerable interest in the valuation process for reporting to the external public. A number of measurement and valuation proposals have been made and are in experimental stages but, as yet, none have gained widespread acceptance. Slow acceptance stems from three perspectives. These include (1) an inadequate appreciation for how valuing intellectual assets can benefit an organization, (2) little agreement on what constitutes IC, and (3) a lack of generally accepted principles for identifying, measuring, and valuing IC.

Reilly (1998) offers a variety of reasons why it is important to establish a value of IC in monetary terms. First, values are necessary for strategic planning and proper management relating to issues such as pricing, licensing, and organizational investments. Second, values are typically required for asset-based financing and the use of intellectual capital assets as collateral. Third, tax planning and compliance require values for amortization, transfer pricing, and other tax-related matters. Finally, values provide useful information for a variety of business decisions ranging from reorganization analysis to dispute resolution related to infringement or fraud. In addition to these reasons, identifying and establishing values for intangible assets (including IC) is required for post-acquisition purchase price allocation accounting.

\section{Assigning Value}

The same three generally-accepted approaches used to value a business can be used to value intangible assets, including IC. These three approaches are typically classified as a market approach, a cost approach, and an income approach (Reilly, 1998). Underlying all of these approaches are usability, marketability, and profitability attributes that affect the valuation of individual IC assets. Utilization of the attributes underlying IC enables an assignment of value by basic valuation approaches.

\section{Market Approach}

The market approach or sales comparison may be the best indicator of value when it relates to arm's-length transactions between independent parties. A drawback of this approach is that intangible assets such as IC do not have organized markets, and finding reliable information on transactions involving assets deemed to be comparable can be challenging. The first step is to research the market to obtain information about sale transactions or offers to purchase or license the asset being valued. Intangible assets typically do not have exact counterparts. Therefore, the next step is to develop units of comparison and perform a comparative analysis. For example, the price per design module or price per software line of code may be developed for a certain type of software and applied to the asset being valued. Based on this analysis, the sale price or conditions of licensure are formulated to reflect the asset being valued. Finally, where multiple value indicators are used, the results from an analysis are combined into a single value or range of values where exact asset counterparts are not available. 
The market approach is considered to be most useful for the valuation of IC assets such as patents or trademarks, where transactional data involving other patents and trademarks that are reasonably comparable to the subject being valued is available. This approach is not as useful in the valuation of human capital, as transactions involving the purchase and sale of a company's assembled workforce, separate and apart from the acquisition of the business as a whole, rarely if ever occur.

\section{Cost Approach}

The cost approach, based on the principle of substitution, can be implemented in two ways by using either reproduction cost or replacement cost. Reproduction cost is the cost to create an exact duplicate of the asset and its related technology. Reproduction cost assumes that the same processes used to create the original asset are used to reproduce it. Replacement cost is the cost to create an asset and related technology that is not identical to the original asset but has usefulness equal to the asset being appraised. Replacement cost assumes that current processes and development methods are used. Therefore, it follows that the replacement asset may have greater utility at lower cost in relation to the appraised asset.

Developing both reproduction and replacement costs will typically provide a range of values within which other factors can be considered. For example, replacement cost may be the maximum amount that a business with the capability to create such assets would be willing to pay. Another factor to be considered is obsolescence. For example, reproduction cost may need to be adjusted because of a decrease in the asset's value due to improvements in technology. Often, both a replacement cost and a reproduction cost cannot be estimated for the particular asset to be valued. For example, reproduction cost for a patent or trademark may be relatively easy to estimate given historical financial data and/or comparable market costs. Reproduction cost would be nearly impossible to estimate for an assembled workforce. A workforce of equal utility could be assembled (thus making the replacement cost method of valuation useful), but a workforce that is identical in all respects to the current workforce is impossible. As a result, replacement cost is the most commonly used valuation method for assembled workforce employed by valuation analysts.

\section{Income Approach}

The income approach, based upon the economic principle of anticipation or expectation, develops a monetary value for an asset by evaluating its impact on a variety of financial measures such as operating income, incremental income, or cash flows. The selection of a financial measure depends on the organization's key success indicators. Once a financial measure has been identified, it can be evaluated in a variety of ways. The financial measures could be evaluated on a "with and without" basis, estimating the changes in the financial measures that would result from (1) not having the asset available such as a patented process, or (2) acquiring the benefits of having the asset.

Income measures are typically discounted or capitalized to determine a present value. This is done either by determining the present value of a specific stream of periodic income flows at an appropriate discount rate (a discounted cash flow analysis), or by capitalizing a single-period income measure into perpetuity (a capitalization of earnings or cash flow analysis.) A discounted cash flow analysis is more appropriate when considering assets such as a patent with a specific useful life. Capitalization of earnings or cash flow is more appropriate when considering the value of an ongoing business or an asset with an indefinite life. The appropriate discount rate is the company's cost of equity capital, incremental borrowing rate, or a weighted average of the two. The key to valuing a particular asset using the income approach is the ability to separate the economic benefits and risks associated with the particular asset from the remainder of the business. This is often difficult in practice. For example, the economic benefit and risk directly attributable to an assembled workforce is difficult to separate from the other assets of a business. For this reason, the income approach is not used in the valuation of certain intangible assets.

IC has been expanded in recent years to include the value of underlying business processes, stakeholder relationships, work-related competencies, customer-related value, and similar intangibles. Many of these measures cannot be stated in monetary terms. Rather, key performance indicators such as employee motivation, customer satisfaction, and process time improvement are being used in continuous improvement efforts and as surrogate means to identify underlying values embedded in the organization. 


\section{Valuing Embedded Intellectual Capital}

Stewart (1997, pp. 224-229) suggests three methods to indirectly determine the value of intellectual capital imbedded in an organization. The three methods include market-to-book ratio, Tobin's q, and calculated intangible value. These methods can be considered indirect valuation methods because these methods attribute a portion of the company's value first to those assets reported on the company's balance sheet. The remaining portion of "unexplained" value is attributable to imbedded intangible assets of the company. The three methods are described briefly with an example of how the method is used in practice.

\section{Market-to-Book Ratio}

The market-to-book ratio assumes that a company's total market value (the market price per share of common stock multiplied by the number of shares outstanding) can be allocated to its tangible and intangible assets. Therefore, the difference between book value shown on the company's balance sheet and market value gives an approximate measure of the total intangible asset value that does not appear on the balance sheet (Sveiby, 1998). This total intangible asset value can be further subdivided into two categories: 1) specifically-identifiable intangible assets, and 2) goodwill value.

The market-to-book value ratio by itself has limited value for several reasons. First, stock prices are affected by many factors, such as positive or negative market psychology, that may not be directly associated with the value of a company's tangible or intangible assets. Second, book values represent depreciated historical costs that rarely coincide with the current fair market value of a company's assets. Thus, the difference between a company's total market value and its book value can be attributed to not only assets that are absent from the balance sheet, but also to undervalued assets that are reported on the balance sheet. This second concern can be alleviated by the use of Tobin's q.

Tobin's $q$

James Tobin, a Nobel Prize-winning economist, developed $q$ as a measure to help predict investment decisions. Tobin's q is essentially the same as the market-to-book ratio except that Tobin used replacement cost of tangible assets rather than book value in the calculation. The theory is that if $\mathrm{q}$ is greater than 1 and greater than competitors' q then the company has the ability to produce higher profits than other similar companies. The company has something such as intangible IC that gives it an advantage.

Tobin's q can be calculated by taking the book value of a company, adding back accumulated depreciation, and making appropriate adjustments in the current value of different classes of assets from the time of purchase. This adjustment process helps narrow the company's value differential to one that can be more reliably attributed to the company's unreported intangible assets.

\section{Capitalized Excess Earnings Method}

An Internal Revenue Service (IRS) Ruling describes a process for estimating the value of goodwill for a variety of purposes. Breweries and distilleries first used this method to calculate the value of goodwill and other intangible assets lost as the result of prohibition. Because the method was originally devised to estimate the intangible value of a business rather than the value of a business as a whole, it's most relevant use today is to allocate the total value of a company between tangible and intangible assets. The method involves five steps:

1. Estimate the net tangible asset value of the company. This typically involves estimating the fair market value of the company's tangible assets, rather than using the net book value of the assets as shown on the balance sheet.

2. Estimate an appropriate fair rate of return on the company's net tangible asset value. The rate of return can be an industry average return on assets or specific rates of return deemed to be appropriate for each tangible asset (or class of asset) comprising net tangible asset value. 
3. Multiply the net tangible asset value by the estimated rate of return for tangible assets. This equals the expected level of earnings produced by the company's tangible assets.

4. Subtract the estimated earnings from tangible assets from the company's total earnings. The difference represents earnings of the company derived from intangible assets.

5. Capitalize the earnings from intangible assets by a risk-appropriate capitalization rate. This produces the estimated total value of intangible assets.

Specifically-identifiable intangible assets, such as patents, could be added to the list of assets for which earnings are estimated in Steps 1 through 3 above. In that case, the resulting value produced in Step 5 would be the value of the company's unidentifiable intangible assets (which could also be described as goodwill).

The calculated intangible value derived above does not have the precision of other asset values reported on the balance sheet, but it is useful in a number of ways. As a benchmark measure, calculated intangible value can help judge whether an organization is fading or is one that has value not reflected in traditional financial measures. Management might view a strong or rising calculated intangible value as an indicator their investment in knowledge assets is paying dividends.

A knowledge-based company with few tangible assets might present the calculated intangible value to their creditor or bank along with their traditional financial statements as evidence of the company's true value. IC isn't collateral in the traditional sense, but its value in creating future cash flows may be more valuable than any other asset displayed in the financial statements.

Economic value added is another valuation procedure that has gained favor among the financial analysts (Barber \& Manger, 2004). This valuation approach values all assets at market prices and then discounts them according to some agreed upon risk-adjusted rate. The appropriate discounted rate is determined according to a market benchmark rate of that risk class, and not according to an ad hoc depreciation rate deemed appropriate by accounting principles. The value of the organization is then calculated as the sum total of the market value of the assets in place and the present value of the growth options of these assets, less any claims of outside creditors. The value of the growth option can be calculated as the discounted value of the future free cash flows expected (where cash flow is the net operating profit after tax, less any prior commitment of funds required to keep the business a going concern).

The economic value added approach is a more intuitive approach to determining the value of the organization as it proceeds to articulate the process that any potential buyer would adopt to determine the true value of a company. The three key estimates are the market value of the tangible assets, the pseudo market value of the organization's personnel, and the appropriate rates of discount for similar risk businesses. Converted into common terminology, the key success factors that need to be measured in assessing the value of the organization are the value of the skills of the human resource assets employed by the organization and the value of the capital provided by the owners of the organization.

\section{COMMUNICATING THE VALUE}

For companies, communicating organizational knowledge and IC will be a difficult task. If organizations are to be successful in the era of information, it is clear that many of the current systems to gather and report the data must change. Companies must identify the intellectual assets necessary for success, develop means for utilizing those assets, and create specific processes to communicate institutional IC to stakeholders. The end result must serve the needs of stakeholders. These needs can vary greatly among different groups of stakeholders, increasing the difficulty of the task of finding a communication structure and framework that serves all groups.

Although approaches to the management of IC will vary greatly across industries and national boundaries, all organizations experience an increasing knowledge-intensive environment. Successful organizations must find a means to leverage IC in the marketplace. Part of the leveraging process will be the dissemination of IC's value to stakeholders. The management discussion and analysis of a company's financial condition and operating results is part of the basic information required by the Securities and Exchange 
Commission (SEC). The SEC requires management to analyze and discuss specific information about the company's liquidity, capital resources, and results of operation. The presentation gives management the opportunity to express the economic consequences of their decisions and the overall condition of the organization. A key element of the discussion is that it is both historical and forward-looking, which presents an ideal forum for communicating the organization's competitive advantage produced by its IC. The management discussion and analysis, also known as the president's report, could provide a brief, objective, and easily readable analysis of the human capital and other intangible assets classed as IC that are a basis of the competitive advantage and wealth creation of the firm. The discussion could describe the innovation, productivity, customer service, and employee involvement within the organization. Measures of innovation, employee involvement, and other performance achievements also relate to the monitoring and achievement of the firm's strategic plan.

Proposed IC financial reporting has three elements - a knowledge narrative, management challenges, and reporting. The purpose of the knowledge narrative is to discuss how the organization intends to ensure that its products or services meet the consumer's needs together with how the resources of the organization will be used to achieve this goal. The management challenges are those that the organization encounters in implementing the knowledge narrative. These challenges initiate a series of action plans that are documented together with the pertinent data created to communicate their success to the public. The reporting element can be either internal or external. When communicating to the external public, a combination of text, figures, graphs, and illustrations can be employed to document how the organization employs IC and as well as typical financial capital.

\section{CONCLUSION}

There is a growing awareness that IC is a key asset for success in today's economic environment. IC is not just data or information in files and databases. It comprises useful knowledge and a competitive advantage for the organization. Effective identification, measurement, and management of IC and its replacement begins with understanding and valuation.

This paper provides a framework to identify and understand the breadth of the concept as well as options to measure, recognize, and report the information to those interested in the organization's activities. Several measurement schemes and approaches were presented showing how IC can be viewed at both the component-bycomponent and organizational levels. The recognition process requires a continuous reappraisal and matching process that goes on within the organization to ensure continued efficiencies and strategic alliance.

Management of IC assets is in its infancy, but interest is growing as fair value models and measurements are being developed and tested. Organizations should initiate efforts to gain an understanding and expertise in managing IC assets for creating future economic and knowledge wealth. However, no model of human resource management or replacement cost reporting can be expected to perform exactly as prescribed. Indeed the emergent view of organizational activities suggests that many unplanned opportunities and threats can emerge. This observation is certainly true with regard to IC and its role in the value of the organization now and in the future. With these caveats, this discussion has attempted to suggest an approximation to how some of the issues surrounding this vital topic may not only be addressed, but also directed to enhance organizational effectiveness. These normative models should be further refined and tested through field research. There is still much to be learned concerning IC and knowledge management.

The important issue is that the present accounting and reporting standards grossly understate the value of the organization's assets and, therefore, provide a skewed financial picture. This is most dangerous for stakeholders in high technology, service, and other organizations where people are key to the organization's success. Designing effective methods of communicating information about value to stakeholders is important at the company level, but accounting and financial reporting standards must be revised in order to provide more useful information to stakeholders globally. 


\section{AUTHOR INFORMATION}

Mary Fischer, Ph.D., Professor, College of Business \& Technology, University of Texas at Tyler, Texas 75799. Her research interest includes financial accounting, nonprofit and government organizations, auditing, and accounting education. E-mail: MFischer@uttyler.edu (Corresponding author)

Treba Marsh, DBA, Professor, Gerald W. Schlief School of Accountancy, Stephen F. Austin State University, Nacogdoches, Texas 75962. Her research interest includes state and local public finance, financial accounting, internal controls, and public budgeting. E-mail: tmarsh@ @fasu.edu

\section{REFERENCES}

1. Barber, E., \& Manger, G. (2004). Improving management's valuation of human capital in small firms. Journal of Management Development, 16(7), 457-465.

2. Brennan, B. A. (1992). Mind over matter: How current accounting practices hobble innovative companies. Harvard Review, May/June, 21-24.

3. Brooking, A. (1996). Intellectual capital: Core asset for the third millennium enterprise. London: International Thomson Business Press.

4. Conference Board. (1997). Communicating corporate performance: A delicate balance. (The Conference Board Report Number 1188-97-RR). New York.

5. $\quad$ Ernst \& Young (E\&Y) (2009). Acquisition accounting-What's next for you? Paris, France: E\&Y.

6. Evinsson, L., \& Malone, M. S. (1997). Intellectual capital: Realizing your company's true value by finding its hidden brainpower. New York: Harper Business.

7. Financial Accounting Standard Board (FASB). (1985). Elements of financial statement. Statement of Financial Accounting Concepts No. 6. Norwalk, CT: FASB.

8. Financial Accounting Standards Board (FASB). (2009). Accounting Standards Codification 350 intangibles other than goodwill. Norwalk, CT: FASB.

9. Financial Accounting Standards Board (FASB). (2009). Accounting Standards Codification 820 fair value measurement. Norwalk, CT: FASB.

10. Government Accounting Standards Board (GASB). (2013). Measurement of elements of financial statements. Norwalk, CT: GASB.

11. Kaplan, R. S., \& Norton, D. P. (1996). The balanced scorecard. Boston: Harvard Business School Press.

12. Lev, B. (2001). Intangibles: Measurement, management and reporting. Washington, D.C.: Brookings Institute Press.

13. Lyles, M. A., \& Schwenk, C. R. (1997). Top management, strategy and organizational knowledge structures, in Lawrence Prusak. Knowledge in organizations. Boston: Butterworth-Heinemann Publishers.

14. McCann, P. (1998). The balanced scorecard: The eleventh commandant, Management Accountant, December, 34-36.

15. McLean, R. (1999). Value creation and value realization: A thought experiment on linking ideas and cash flow. Presentation to the IGM Gathering 2, San Francisco. February.

16. Reilly, R. F. (1998). The valuation of proprietary technology, Management Accounting, January, 45-49.

17. Skandia. (1995). Visualizing intellectual capital in Skandia. Supplement to Skandia's 1994 Annual Report.

18. Stewart, T. A. (1997). A intellectual capital: The new wealth of organizations. New York: Doubleday Currency.

19. Sveiby, K. E. (1998). Intellectual capital thinking ahead. Australian CPA, June, 24-26.

20. Ulrich, D. (1997). Human resources champions: The next agenda for adding value and delivering results. Boston: Harvard Business School Press. 